\title{
Retroperitoneal schwannoma misdiagnosed as an ovarian malignancy
}

\author{
Dong Hyu Cho
}

Department of Obstetrics and Gynecology, Chonbuk National University Medical School, Jeonju, Republic of Korea

\section{Correspondence to} Professor Dong Hyu Cho, obgyn2001@jbnu.ac.kr

Accepted 9 July 2018

\section{SUMMARY}

A 55-year-old woman presented to the hospital with abdominal discomfort over 3 months. Contrastenhanced abdominal CT showed a $10 \times 9 \times 6.5 \mathrm{~cm}$ sized well-defined solid-cystic enhancing mass in the right pelvic cavity. Under general anaesthesia, exploratory laparotomy was performed on suspicion of ovarian malignancy. Pathological examination revealed a retroperitoneal schwannoma with highly ordered cellular component (Antoni A) and hypocellularity with predominantly loose myxoid component (Antoni B). On immunohistochemical staining, the sample showed typically positive result for S-100 in the cytoplasm of the tumour cells. Schwannomas are consisting only of Schwann cells and are most often non-malignant tumors. It is relatively slow growing and usually located in the head, neck and the extremities. Schwannomas are quite rare in the retroperitoneal region. The diagnosis of retroperitoneal schwannomas is often delayed and misdiagnosed as an adnexal tumour, especially locating in the pelvic cavity. Surgical complete resection of tumour is the treatment of choice and recurrence is unusual after complete resection.

\section{DESCRIPTION}

A 55-year-old woman presented to the hospital with abdominal discomfort for 3 months. A hard, fixed mass as large as two fists was palpated in the right lower abdomen on pelvic examination.

Contrast-enhanced abdominal CT showed a $10 \times 9 \times 6.5 \mathrm{~cm}$ sized well-defined solid-cystic enhancing mass in the right pelvic cavity (figure 1A). PET-CT showed a fluorodeoxyglucose-avid solid mass in the right ovarian fossa (figure 1B).

Under general anaesthesia, exploratory laparotomy was performed on suspicion of an ovarian malignancy. The uterus and both adnexa appeared normal, but a mass, the size of two fists, was found
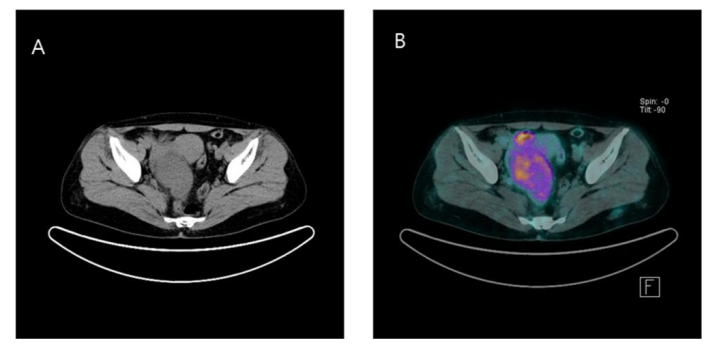

Figure 1 (A) Contrast-enhanced abdominal CT reveals a $10 \times 9 \times 6.5 \mathrm{~cm}$ sized well-defined solid-cystic, hyperechogenic enhancing mass in the right pelvic cavity. (B) PET-CT shows fluorodeoxyglucose-avid solid mass in the right ovarian fossa.


Figure 2 Intraoperative findings: (A) a mass, the size of two fists, in the right retroperitoneal space close to the right adnexa. (B) Complete resection was performed.

in the right retroperitoneal space. No enlargement of lymph node around the mass nor metastasis was found. Intraoperative frozen section analysis suggested a benign mesenchymal tumour. Complete surgical resection was performed (figure 2).

Macroscopic examination revealed an $11 \times 7 \times 6.4 \mathrm{~cm}$ sized capsulated mass with solid, bright-yellow areas (figure 3A). Pathological examination revealed a retroperitoneal schwannoma with a highly ordered cellular component (Antoni A) and hypocellularity with a predominantly loose myxoid component (Antoni B). Immunohistochemical staining showed a predominantly positive result for S-100 in the cytoplasm of the tumour cells (figure $3 \mathrm{~B}$ ). After surgery, our patient is doing fine and no disease recurrence has occurred so far.

Schwannomas consist only of Schwann cells and are most often non-malignant tumours. The tumours are relatively slow growing and usually located in the head, neck and extremities. Schwannomas are quite rare in the retroperitoneal region. The disease occurs in individuals of all ages, with most cases diagnosed in people between the ages of 20 and $60 .^{1}$ The symptoms of schwannomas are highly non-specific and vary depending on the location and size of the lesion. The diagnosis of retroperitoneal schwannomas is often delayed
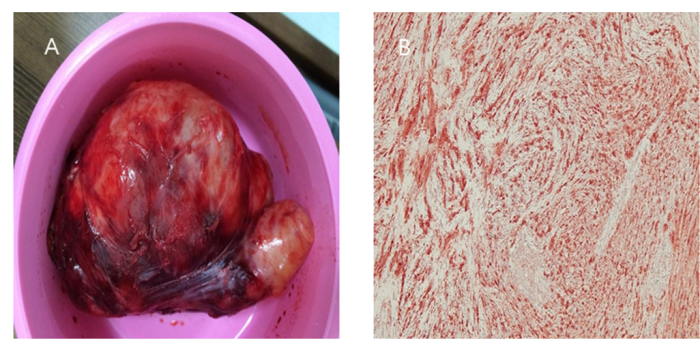

Figure 3 Gross finding and microscopic features of retroperitoneal schwannoma. (A) Capsulated solid mass after resection. (B) Classical palisade pattern in specific regions (Antoni $A$ ), loose myxoid component (Antoni $B$ ) and S-100 positivity of Schwann cells $(\times 200)$. 


\section{Learning points}

Schwannoma is a benign nerve sheath tumour composed of Schwann cells covering the peripheral nerves.

- The majority of schwannoma is found incidentally and misdiagnosed as other conditions both clinically and radiologically.

- We emphasise that it is necessary to attempt to differentiate the tumour origination from the retroperitoneal cavity when an adnexal tumour is detected.

and misdiagnosed as an adnexal tumour, especially due to the location in the pelvic cavity. The symptoms of schwannomas are highly non-specific and vary depending on the location and size of the lesion, such as abdominal discomfort, abdominal fullness or neurological symptoms. ${ }^{2}$

Complete surgical resection of the tumour is mandatory to avoid tumour recurrence, but care should be taken to avoid damaging surrounding neurovascular structures. Conservative surgery may be performed instead to avoid damage to the surrounding blood vessels and nerve tissue, but the prognosis for this treatment is controversial.

Contributors DHC participated sufficiently in the work, including preparation of manuscript, and agreed to accept equal responsibility for the accuracy of the contents of the paper.

Funding The author has not declared a specific grant for this research from any funding agency in the public, commercial or not-for-profit sectors.

Competing interests None declared.

Patient consent Obtained.

Provenance and peer review Not commissioned; externally peer reviewed.

\section{REFERENCES}

1 Strauss DC, Qureshi YA, Hayes AJ, et al. Management of benign retroperitoneal schwannomas: a single-center experience. Am J Surg 2011;202:194-8.

2 Chen $\mathrm{CH}$, Jeng CJ, Liu WM, et al. Retroperitoneal schwannoma mimicking uterine myoma. Taiwan J Obstet Gynecol 2009;48:176-7.

Copyright 2018 BMJ Publishing Group. All rights reserved. For permission to reuse any of this content visit http://group.bmj.com/group/rights-licensing/permissions.

BMJ Case Report Fellows may re-use this article for personal use and teaching without any further permission.

Become a Fellow of BMJ Case Reports today and you can:

- Submit as many cases as you like

- Enjoy fast sympathetic peer review and rapid publication of accepted articles

- Access all the published articles

- Re-use any of the published material for personal use and teaching without further permission

For information on Institutional Fellowships contact consortiasales@bmjgroup.com

Visit casereports.bmj.com for more articles like this and to become a Fellow 